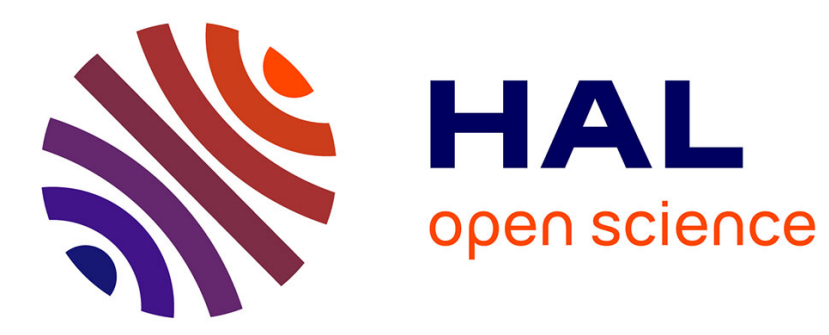

\title{
Descriptions, truth value intuitions, and questions
}

\author{
Anders J. Schoubye
}

\section{To cite this version:}

Anders J. Schoubye. Descriptions, truth value intuitions, and questions. Linguistics and Philosophy, 2010, 32 (6), pp.583-617. 10.1007/s10988-010-9069-y . hal-00577970

\section{HAL Id: hal-00577970 \\ https://hal.science/hal-00577970}

Submitted on 18 Mar 2011

HAL is a multi-disciplinary open access archive for the deposit and dissemination of scientific research documents, whether they are published or not. The documents may come from teaching and research institutions in France or abroad, or from public or private research centers.
L'archive ouverte pluridisciplinaire HAL, est destinée au dépôt et à la diffusion de documents scientifiques de niveau recherche, publiés ou non, émanant des établissements d'enseignement et de recherche français ou étrangers, des laboratoires publics ou privés. 


\title{
Descriptions, truth value intuitions, and questions
}

\author{
Anders J. Schoubye
}

Published online: 18 March 2010

(C) Springer Science+Business Media B.V. 2010

\begin{abstract}
Since the famous debate between Russell (Mind 14: 479-493, 1905, Mind 66: 385-389, 1957) and Strawson (Mind 59: 320-344, 1950; Introduction to logical theory, 1952; Theoria, 30: 96-118, 1964) linguistic intuitions about truth values have been considered notoriously unreliable as a guide to the semantics of definite descriptions. As a result, most existing semantic analyses of definites leave a large number of intuitions unexplained. In this paper, I explore the nature of the relationship between truth value intuitions and non-referring definites. Inspired by comments in Strawson (Introduction to logical theory, 1964), I argue that given certain systematic considerations, one can provide a structured explanation of conflicting intuitions. I show that the intuitions of falsity, which proponents of a Russellian analysis often appeal to, result from evaluating sentences in relation to specific questions in context. This is shown by developing a method for predicting when sentences containing nonreferring definites elicit intuitions of falsity. My proposed analysis draws importantly on Roberts (in: Yoon \& Kathol (eds.) OSU working papers in Linguistics: vol. 49: Papers in Semantics 1998; in: Horn \& Ward (eds.) Handbook of pragmatics, 2004) and recent research in the semantics and pragmatics of focus.
\end{abstract}

Keywords Truth value intuitions - Definites - Questions · Prosodic focus · Topic $\cdot$ Presuppositions $\cdot$ Semantics $\cdot$ Pragmatics

In contemporary philosophy of language and linguistics, two mutually incompatible semantic analyses of definites are predominant. These are of course Russell's (1905) famous quantificational analysis and the presuppositional analysis as defended by Strawson $(1950,1952,1964) .{ }^{1}$ The focal point of disagreement between these analyses is whether definites should be analyzed as asserting or merely presupposing

1 With the important precursors to the presuppositional analysis appearing in Frege $(1892,1918)$.

A. J. Schoubye $(\bowtie)$

Arché, University of St Andrews, St Andrews, Scotland, UK

e-mail: ajs244@st-andrews.ac.uk, schoubye@gmail.com 
the existence of an individual satisfying the relevant description. In the profusion of spirited defenses of these analyses, appeals to truth value intuitions are fairly common. For proponents of a Russellian analysis, the intuition of falsity elicited by a sentence such as (1) is often considered an argument in favor of an existential analysis - an analysis on which sentences containing non-denoting descriptions are assigned a classical truth-value. In contrast, for proponents of a Strawsonian analysis, the fact that no clear truth value intuition is elicited by sentences such as (2) is considered an argument in favor of a presuppositional analysis - an analysis on which sentences containing non-denoting descriptions are undefined, viz. neither true nor false.

(1) The king of France shot my cat last night.

(Neale 1990)

(2) The king of France is bald.

(Strawson 1964)

The immediate problem is that these variations in truth value intuitions are pervasive and as a result many researchers today maintain that (a) truth value intuitions are too unstable to provide decisive support for either analysis, (b) that providing an explanation of these pervasive variations is essentially intractable, and (c) that appeals to truth value intuitions merit no serious attention. In other words, truth value intuitions have acquired a bad reputation. ${ }^{2}$

But simply disregarding these putative semantic intuitions is not obviously feasible. Both the existential and the presuppositional analyses provide uniform treatments of no-reference cases, and as a result a wide variety of cases are left unexplained on both analyses. This is unsatisfactory for several reasons, but one particular reason is that an important factor in assessing the adequacy of a semantic analysis is its predictive capabilities. Yet, given that both the existential and the presuppositional analyses give uniform treatments of no-reference cases, the result is numerous incorrect predictions.

One way to resolve the problem of apparently conflicting intuitions is to take the existence of these fragile, highly context-sensitive, and frequently unstable intuitions as constituting a direct argument against both aforementioned analyses. This option amounts to the claim that only a non-uniform analysis of definites, i.e. an analysis which is capable of assigning both classical and non-classical truth values to sentences containing non-referring definites, will be adequate, see e.g. Lasersohn (1993). However, another option, available to both proponents of Russell's theory

\footnotetext{
2 Occasionally, the problem is categorically dismissed. For instance, in his book Descriptions, Neale (1990) writes.

[...] all sorts of factors may conspire to deter the native speaker from saying that a given utterance is true or false, but that is hardly enough to show that the utterance lacks a truth-value. (Neale 1990, p. 28)
}

While Neale is right that the existence of no-reference cases which elicits no robust intuitions is insufficient for concluding that a given sentence lacks a truth value, Neale neglects to consider which factors might deter the native speaker from saying that a given utterance is neither true nor false. This paper is an attempt to explore and explain why we should believe that such factors exists and what they are. 
and proponents of Strawson's theory, is to combine the analyses with a systematic explanation of the problematic cases, e.g. an explanation which justifies disregarding certain parts of the data. Such an approach would be successful if it was effectively demonstrated that parts of the putative semantic data are semantically irrelevant.

While investigating the behavior of truth value intuitions is in itself instructive, this paper is an attempt to explore the second option. In particular, it's is an attempt to explain why truth value intuitions exhibit such extensive variations and in turn evaluate to what extent a semantic analysis of definites can and should rely on such intuitions. The aim is to show that in order to make sense of these recalcitrant truth value intuitions, an alternative perspective on the putative data, so far neglected in the debate, is required. The upshot of my analysis is that the fairly commonplace intuitions of falsity associated with sentences containing nonreferring definites quite often result from factors which are not semantically relevant. This yields, ceteris paribus, reasons to favor a presuppositional analysis of definites. ${ }^{3}$

The hypothesis in this paper is that intuitions of falsity elicited from sentences suffering from existential presupposition failure are a result of evaluating the content of the sentences in relation to a contextually salient question. In particular, I show that there is an important relation between robust intuitions of falsity and the satisfaction of certain conversational conditions. I argue that the existence of this relation puts into question whether these intuitions track the semantic status of the sentences in question. The proposal here is essentially an attempt to revive and systematize important insights made by Strawson (1964) while avoiding certain problematic consequences of his proposed solution.

I begin the paper by briefly illustrating the complexity of the phenomenon to be explained. The data shows quite vividly that there is no simple or obvious systematic pattern which provides an easy explanation of the variance in intuitions. Next, I briefly discuss a couple of recent attempts to explain the behavior of truth value intuitions, and argue that these proposals are problematic in various respects. In light of these proposals, I contend that to gain a better understanding of the behavior of truth value intuitions, we must first consider their behavior in context, namely their sensitivity to discourse topics and to salient questions. Adopting Roberts' (1998, 2004) framework for discourses, I show how intuitions are systematically sensitive to context, and that there is an important connection between intuitions of falsity and, what I label, conversational consonance. Subsequently, I study what happens when non-referring definites interact with prosodic focusing. The effects of prosodic focus are perplexing and a neglected phenomenon in recent discussions of the problem. However, I show that the present proposal provides a straightforward explanation of these effects. Finally, I evaluate the explanatory adequacy of the proposal.

\footnotetext{
3 If your favored semantic analysis of presuppositions is couched in a dynamic framework, I'm here advocating the view that non-referring definites, pace presupposition accommodation, incur update crashes.
} 


\section{The intuitive pull}

First a bit of useful terminology: I use the abbreviation SWEPF for Sentences With Existential Presupposition Failure. This is merely a choice of words and it's interchangeable with e.g. sentences containing non-referring definites or similar. I use the term robust truth value intuitions (or sometimes just robust intuitions), to refer to intuitions of falsity or (in rare cases) intuitions of truth, however I focus almost exclusively on cases which elicits robust intuitions of falsity. I use Strawson's term squeamish to refer to SWEPFs which elicit no robust intuitions, i.e. squeamish SWEPFs. These are SWEPFs where one feels an immediate inability to judge the sentence either true or false-i.e. the SWEPF elicits a feeling of squeamishness.

\subsection{The data}

The paradigm case of a SWEPF which elicits squeamishness is Strawson's famous example (2).

(2) The king of France is bald.

(Strawson 1964)

An immediate inability to evaluate this sentence for truth or falsity is a common reaction-the reaction that is normally reported in the literature. Confronted with (2), there is an intuitive sense that the speaker has made a mistake and that one cannot simply dismiss the sentence as false. In other words, it appears to elicit no robust intuitions. However, a small tweak of the content in (2) seems to make intuitions change.

(3) The king of France is a skinhead.

(4) The king of France is a bald nazi.

These SWEPFs differ from (2) in that they seem to elicit a much stronger sense of falsity and there is thus a marked contrast between (2) and (3)-(4).

Let's consider another contrast pair. The SWEPFs in (5) and (6) are standard examples of SWEPFs which elicit robust intuitions of falsity. Assume that the demonstratives below pick out contextually salient objects.

(5) The king of France is sitting in that chair.

(Lasersohn 1993)

(6) The king of France owns that pen.

(von Fintel 2004)

While these SWEPFs elicit robust intuitions of falsity, a change in intuition is again facilitated by a seemingly insignificant change of the content, e.g. (7-8).

(7) The king of France is sitting in a chair.

(8) The king of France owns a pen.

(von Fintel 2004) 
If these sentence do not elicit straightforward squeamishness, I think the pull towards squeamishness is certainly non-negligable. If so, there is again a distinct contrast between (5-6) and (7-8).

From the point of view of semantic analysis, the above SWEPFs seem to suffer from the same defect, namely that the definite description fails to refer. One would therefore prima facie expect our intuitions to be uniform, yet they are clearly not. There are numerous contrast cases such as the above and below I provide a select sample of relevant cases. Since the data is somewhat fine-grained, contrast cases are particularly useful for demonstrating the peculiar variances in intuitions. What's important at this point is to consider the intuitive pull of the sentences. These minimal pairs show how sentences which are structurally quite similar nevertheless pull intuitions in different directions. ${ }^{4}$

SWEPFs (Sentences With Existential Presupposition Failure)

$$
\#=\text { Squeamishness } \quad F=\text { Falsity }
$$

(2) \# The king of France is bald.

(4) ${ }^{F}$ The king of France is a bald nazi.

(7) \# The king of France is sitting in a chair.

(5) $F$ The king of France is sitting in that chair.

(8) \# The king of France owns a pen.

(6) $F$ The king of France owns that pen.

(9) \# The king of France is on a state visit.

(10) $F$ The king of France is on a state visit to Australia this week.

(11) \# The king of France heard about Goldbach's conjecture.

(12) $F$ The king of France proved Goldbach's conjecture.

\footnotetext{
${ }^{4}$ I adopt von Fintel's (2004) convention of using '\#' to indicate feelings of squeamishness and a superscripted ' $F$ ' to indicate intuitions of falsity. Many of these examples are collected or adopted from the existing literature on truth value intuitions, i.e. Lasersohn (1993), von Fintel (2004), and Yablo (2006, 2009).
} 
(13) \# The king of France read Anna Karenina.

(14) $F$ The king of France wrote Anna Karenina.

(15) \# The king of France always enjoys a croissant in the morning.

(16) $F$ The king of France always enjoys some human flesh in the morning.

(17) \# The king of France walked his dog last night.

(18) $F$ The king of France ate his dog last night.

(19) \# The king of France is BALD. ${ }^{5}$

(20) $F$ The king of FRANCE is bald.

(21) \# The king of France is on a STATE visit.

(22) $F$ The king of FRANCE is on a state visit.

(23) \# The king of France is bald.

(24) $F$ Only the king of France is bald.

Briefly surveying the above contrast pairs makes perfectly clear the complexity of the problem. Let's consider some of the apparently intuition-changing causes. In (2) the change in intuitions appears to be caused by the addition of the noun 'nazi'. However in (5-7) and (6-8) the intuition-changing factor is the difference between the indefinite determiner and the demonstrative. In (11-12) and (13-14) intuitions change due to a mere substitution of verbs, whereas in (19-20) and (21-22) intonational stress forces an intuition of falsity. In (24), the focus-sensitive particle 'only' has a similar effect. In light of these cases, it seems that hopes of finding some simple structural explanation are quickly dashed. While it's possible to formulate somewhat intuitive but ad hoc explanations for isolated cases, providing a uniform explanation is a real challenge. Yet, if our semantic analysis is to capture the data and refrain from making incorrect predictions, a uniform explanation is clearly preferable, if not required.

\subsection{Accommodation theories}

In recent years, a couple of interesting proposals to explain the behavior of truth value intuitions and their significance to semantics have emerged, namely

\footnotetext{
5 The capitals here indicate a pitch accent.
} 
Lasersohn (1993), von Fintel (2004), and Yablo (2006, 2009). ${ }^{6}$ While these theories are different in various respects, they converge on a general idea. The common contention is that truth value intuitions in no-reference cases are a result of a mechanism of temporary accommodation of the false presupposition. When evaluating SWEPFs, evaluators (i.e. individuals consulting their intuitions) employ a temporary accommodation of the presupposition to permit an evaluation of the content of the SWEPF. The hypothesis is that if the result of accommodating the presupposition is a proposition which the speaker is in a position to falsify by deriving a contradiction, the sentence elicits an intuition of falsity. Conversely, if the speaker is unable to falsify the proposition, e.g. not in a position to derive a contradiction, the sentence is predicted to elicit no robust truth value intuition. On Lasersohn's (1993) and von Fintel's (2004) proposals, this basic idea is formally explicated in terms of belief revision procedures; the false presupposition is added to the evaluator's body of beliefs and the sentence under evaluation is tested against this body of beliefs. ${ }^{7}$ If the evaluator is in a position to derive an inconsistency after (a) accommodating the false presupposition and (b) adding the propositional content of the relevant sentence, the SWEPF is judged false. If the evaluator is not in a position to derive an inconsistency, the SWEPF is predicted to elicit squeamishness. ${ }^{8}$ Consequently, these proposals share the basic assumption that truth value intuitions must be explained in terms of a verification/falsification procedure.

While these proposals capture considerable parts of the data, I believe the general strategy is problematic. I'll briefly discuss what I take to be the two primary problems. First, there is a class of cases for which these proposals yield systematically incorrect predictions and these incorrect predictions stem solely from the

\footnotetext{
${ }^{6}$ There are important differences between these three analyses, but the objections I discuss here are sufficiently general to apply to all three proposals. Two papers that also deserve mentioning are Glanzberg (2005) and Geurts (2007). Glanzberg's paper is a proposal to characterize the conditions under which a sentence fails to express a proposition and it touches briefly on the topic of truth value intuitions and presupposition failure. Glanzberg's general contention is that truth value intuitions are too unstable to provide solid data for theorizing and he suggests instead to rely on a range of discourse-based tests, socalled repair tests. This line of reasoning is similar to the proposal I present here, but since Glanzberg's paper is not an attempt to explain the peculiar behavior of truth value intuitions, it engages with a very limited number of examples. Geurts (2007) defends a Strawsonian analysis of strong determiners and contends that Strawson's view of presuppositions should be assimilated to the binding theory of presuppositions, cf. (van der Sandt 1992). In this paper I also defend a broadly Strawsonian analysis, but I do not discuss Geurts' proposal since it fails to engage with, and cannot explain, a number of the cases introduced in e.g. Fintel (2004). Moreover, since Geurts' proposed analysis is quite similar to Strawson's, I believe it falls prey to a number of the problems that afflicts Strawson's original proposal. These problems are discussed in von Fintel's paper. So, while I'm sympathetic to the overarching idea in Geurts' paper, I believe the proposal presented here provides a more satisfactory analysis.

7 Providing a detailed account of the relevant belief revision procedure faces a number of challenges. For instance, bodies of beliefs must be closed under some suitable consequence relation, but adequately characterizing that consequence relation is obviously no trivial task. Nevertheless, to attain correct predictions, an adequate characterization is required. The most comprehensive attempt to provide an adequate characterization of the belief revision procedure is given in von Fintel (2004). I'll ignore problems related to this issue for the remainder of this paper.

8 The crucial differences between these proposals lie in their explications of the revision procedure. However, the problems related to these approaches are sufficiently general, so that we can ignore these differences here. The proposals also diverge importantly in their assessments of the semantic significance of these intuitions, but I'll also ignore these differences.
} 
limitations of the strategy, namely the verification/falsification strategy which is based on whether inconsistencies are derivable. The existence of this class puts into question whether a verification/falsification strategy is equipped to explain how truth value intuitions are in general generated. Let's begin by considering a number of the SWEPFs listed above. Using the verification/falsification procedure, the accommodation theories make correct predictions for the paradigm cases (2) and (5). Adding to our stock of beliefs that there is a king of France and that he is bald, gives rise to no inconsistency and hence is predicted to elicit squeamishness. Conversely, adding to our stock of beliefs that there is a king of France and that he is sitting in a contextually salient chair does give rise to an inconsistency. Either the relevant chair is empty or it's occupied by someone who we know is not the king of France, and so, doing simple derivations on our body of beliefs, we quickly derive a contradiction. This is the desired result, since (5) elicits an intuition of falsity. ${ }^{9}$

However, when we start considering additional cases, these proposals run into problems. First, a number of the listed contrast cases cannot be explained by these proposals. For instance, the stark contrast between (2) and (3-4) is undetected by the verification/falsification analysis; while there is no way of falsifying that the king of France is bald (i.e. deriving a contradiction), there is also no way of falsifying that he is a bald nazi. Analogous results obtain for the contrast pairs (15-16) and (17-18). To explain the contrast between e.g. (2) and (4), the accommodation theories must place heavy demands on bodies of beliefs; they must assume that bodies of beliefs in general contain a proposition which is either inconsistent with (4) or has an entailment that is inconsistent with (4). To capture the contrast, they must therefore either attribute to speakers a general belief such as 'no kings are nazis' or the more odious belief 'the king of France is not a nazi'. Now, I take it as a datum that it's simply not feasible to ascribe the latter belief to speakers in general. As regards the former, viz. the general belief that no kings are nazis, the question arises whether it's reasonable to assume that speakers in general have such a belief. This is, to say the least, unclear. However, simply assuming that they do, only because (4) elicits an intuition of falsity, deprives the proposals of explanatory power. In that case we're attributing beliefs to people simply to attain correct predictions, but if the proposals are to explain intuitions, we need independent justification for the assumption that speakers in general have such beliefs. It's rather difficult to see what would justify that assumption.

Now, because these analyses rely on verification/falsification, they rely crucially on facts-facts which are in general known. But this means that if the facts required to falsify a sentence are not known (or on von Fintel's account, something that could not in principle be known), the sentence is predicted to elicit a sense of squeamishness. As a result, any sentence which ascribes e.g. a non-factive mental state (i.e. a non-factive propositional attitude) to a non-referring definite is predicted to elicit squeamishness. There are of course no facts about what, say, the king of France's mental states are, and as a result we have no beliefs about the mental states

\footnotetext{
9 It should be noted that von Fintel's (2004) revision procedure is more sophisticated than e.g. Lasersohn's (1993) which allows him to capture more data. Nevertheless, the cases adduced below are problematic for both Lasersohn, von Fintel, and Yablo.
} 
of the king of France (presumably because he doesn't exists). Consequently, any sentence of that form should elicit a sense of squeamishness. Nevertheless, constructing examples of that form which elicit robust intuitions of falsity is an easy task. Consider the cases below.

$F$ The king of France hates your mother.

(26) $F$ The king of France is planning a nuclear attack on the US.

$F$ The king of France wants to steal your car.

These sentences seem to me to elicit robust intuitions of falsity, but because of the inherent limitations of the verification/falsification strategy, the accommodation theories cannot predict this. These results constitute a real challenge to the claim that we're somehow relying on a tacit verification/falsification procedure when generating these intuitions. It's just not clear that verification/falsification is at issue here.

This brings us to what I consider the other primary problem with the accommodation theories. On these analyses, no explanation is provided of the fragility of truth value intuitions. Many SWEPFs elicit no robust intuitions when considered in isolation, but suddenly elicit quite robust intuitions of falsity when considered in context. In other words, truth value intuitions are delicate and easily affected by contextual factors. Any analysis attempting to explain the behavior of these delicate intuitions that nevertheless fails to explain their significant sensitivity to context is bound to be afflicted with predictive shortcomings. Because the accommodation theories have no resources to explain such variations, there are numerous cases of SWEPFs whose behavior in context remains but a mystery. Given a SWEPF and a relevant body of beliefs, the accommodation theories make a firm prediction, and as long as the context engenders no change in the body of beliefs, this prediction remains the same. But, as I'll demonstrate in the next section, context can engender a change in truth value intuitions without altering in any substantial way the relevant body of beliefs. ${ }^{10}$ The accommodation theories are at a loss to explain this kind of variation.

I submit that if we are to have any hope of sorting out this mess, we must focus our attention elsewhere, viz. away from SWEPFs evaluated in isolation. If we want to gain a better understanding of truth value intuitions in regards to SWEPFs, we must examine their behavior in context.

\subsection{Systematizing the Strawsonian insights}

My proposal is very much an elaboration of ideas put forward in Strawson's seminal (1964) paper. I take my analysis to be a rigorous systematization of Strawson's main insights which avoids the unfortunate consequences of his proposed solution. Strawson originally cast his solution to the problem in terms of a distinction

\footnotetext{
$\overline{10}$ Relevant cases here include (28) and (29).
} 
between topic and focus, and he conjectured that intuitions of falsity are elicited only when non-referring definites are not in topic position. He therefore proposed to analyze definites in focus position as non-presuppositional, since this would allow these sentences to be assigned classical truth values in accordance with our purported intuitions. However, Strawson's proposal is problematic on several counts. First, it's convincingly argued in e.g. von Fintel (2004) that definites are presuppositional irregardless of their sentence topic/focus placement. ${ }^{11}$ Secondly, on Strawson's proposed method for identifying sentence topics, his proposal makes a number of incorrect predictions. Many sentences elicit strong intuitions of falsity even though the non-referring definite is in, what Strawson considered, topic position. ${ }^{12}$ The present analysis is designed to avoid these consequences while retaining the basic idea in Strawson, namely that discourse topics, or rather questions under discussion, play an essential role in generating intuitions.

\section{SWEPFs in context}

The accommodation theories afford little attention to the influence of context on truth value intuitions. The tacit assumption is that contextual information plays no significant role, since conflicting intuitions are elicited even when no explicit contextual information is supplied-as witnessed in the contrast pairs listed earlier. It's therefore presupposed that it's sufficient to provide an explanation of isolated SWEPFs, or in Strawson's words, SWEPFs evaluated as 'asserted abruptly and out context' (Strawson 1964, p. 68). Nevertheless, explaining how minor variations in sentence content and sentence form are capable of affecting intuitions in such a remarkable way has proved exceedingly complicated, so in this section, I want to explore and discuss the behavior of truth value intuitions in context. The hope is that this will provide important insights into their curious behavior.

An interesting characteristic of squeamish SWEPFs, that is SWEPFs which are liable to elicit a sense of squeamishness when asserted abruptly and out of context, is the ease with which these sentences are transformed into SWEPFs which elicit an immediate sense of falsity. In particular it seems that only minimal contextual framing is required to transform a sense of squeamishness into a robust intuition of falsity. To illustrate this, consider the cases below.

(2) \# The king of France is bald.

(8) \# The king of France owns a pen.

11 Cf. the 'Hey, Wait a Minute!'-test (Fintel 2004, pp. 322-325).

12 Whether the topic/focus interpretation of Strawson's proposal is correct is somewhat controversial. This is the predominant interpretation of Strawson in the literature, but some authors, e.g. Anne Bezuidenhout (p.c.) and Kadmon (2001) suggest alternative interpretations. Kadmon (2001, p. 402ff) contends that Strawson has in mind questions under discussion, rather than topic/focus and on that interpretation, my proposal is very much an elaboration of Strawson's suggestions. 
\#The king of France always enjoys a croissant in the morning.

Without any contextual information, these sentences are liable to elicit a feeling of squeamishness, i.e. an inability to evaluate them for truth or falsity. However, with a minimal amount of contextual information, the sentences are quickly transformed into robust SWEPFs. Here's a simple case. Suppose you're compiling a list of every monarch in Europe who owns a pen. Suppose someone utters (8). ${ }^{13}$ In this context, when evaluating the sentence in relation to a salient question, the assertion seems to elicit an intuition of falsity. Asserted abruptly and out of context, that sentence elicits squeamishness, but this minor tweak in the context seems to change intuitions. In other words, we don't need much from context to get falsity judgments. To drive the point home, I present two cases where a suitably enriched context appears to facilitate falsity intuitions. These enriched context do not have any relevant effect on bodies of beliefs. In other words, the accommodation theories discussed in the previous section have no explanation for these variations.

\section{Context I}

The famous hair-dresser, Pierre, is organizing a fashion show, where the hair-models are all European royalty. Incidentally, minimalism is the new black in hair-style fashion, so Pierre is trying to determine whether he can convince some royality to go bald for the show. As he's deliberating, he turns to you and his other assistants and says: I can't think of any royal who would agree to go bald just for the sake of the fashion show, and I can't think of any who is already bald. You guys get on this immediately. Whoever finds a solution gets to go to the fashion show. Another assistant standing next to you exclaims: 'The king of France is bald'.

I think there's a natural inclination here to judge that the assistant's utterance of (2) is straightforwardly false. Now, recall that (2) is the paradigm example of a sentence that elicits no robust intuitions when asserted abruptly and out context. Here is another example.

\section{(29) Context II}

A salesman from the company Froggy Croissants is attempting to persuade you that your high-end bakery should start selling croissants from Froggy Croissants. You're sceptical and say: 'The problem is this. Our customers are primarily wealthy snobs with poor taste who only buy products which are trendy or hip. So, unless Paris Hilton or some other celebrity is eating croissants on a regular basis, we won't be able to sell them' The salesman retorts: 'I take your point, but you see, our product is extremely popular in France. For instance, the king of France always enjoys a croissant in the morning'.

\footnotetext{
13 Strawson uses the example 'What examples, if any, are there of famous contemporary figures who are bald?'. These cases are often noted in the literature, but proposals to explain these cases are fairly infrequent.
} 
When (15) is embedded in the above context, it seems to me that it's natural to again judge it straightforwardly false. Again, observe that this sentence elicits no robust intuitions when evaluated without explicit contextual information.

The principal question is why intuitions change in the above contexts. It's easily recognized that not any addition of contextual information is sufficient for achieving an intuition-changing effect, and that the context must be primed in a suitable way. For instance, suppose that the salesman in the latter context retorted by uttering I take your point, but you see, our product is extremely popular in France. For instance, the king of France is bald. While this would be a very odd thing for the salesman to say, indeed a clearly inappropriate assertion, I think there is no sense in which a robust judgment of falsity automatically results. Yet, it takes little imagination to construct utterance contexts which are suitable for changing a sense of squeamishness into a robust intuition, so the question remains.

In addition to contextual framing, there are other curious ways of altering intuitions. For instance, prosodic focus is often noted to have effects similar to those observed with contextualized SWEPFs. Consider the sentences in (30-32) — capitals indicate a pitch accent.

\section{$F$ The king of FRANCE is bald.}

$F$ The king of FRANCE owns a pen.

$F$ The king of FRANCE always enjoys a croissant in the morning.

Here I think there is a rather striking contrast between the sentences above and their unfocused counterparts. In particular, when the non-referring determiner phrase is focused, indicated above by a pitch accent on the proper name 'France', these sentences pull immediate intuitions towards falsity. This is surprising, because it's standardly assumed that absent certain focus-sensitive particles (e.g. 'only'), focus has no truth conditional effects. Nevertheless truth value intuitions appear to be affected by the focus. ${ }^{14}$

Similar perplexing effects on truth value intuitions are observed with certain syntactic constructions, e.g. clefts.

$$
{ }^{F} \text { It is the king of France who is bald. }
$$

\footnotetext{
${ }^{14}$ For the accommodation theories, which purport to explain intuitions of falsity in terms of inconsistencies, this data is particularly problematic. While focus is assumed to have the semantic effect that a set of contextually constrained alternatives is computed, it's unclear how such a set of alternatives is to be used to derive an inconsistency. There is therefore no obvious way for the accommodation theorists to explain the effects of prosodic focusing on truth value intuitions. I'm grateful to Nate Charlow for making this point more clear to me.
} 
Again, I think there's a strong pull towards falsity here rather than squeamishness. Notice that the existential presupposition triggered by the cleft should not affect our intuitions here, since it's perfectly compatible with our knowledge that someone is bald. ${ }^{15}$

In the remainder of this paper, I provide an alternative explanation of the relation between truth value intuitions and SWEPFs and I propose a tentative procedure for predicting when SWEPFs elicit intuitions of falsity or at least pull our intuitions in the direction of falsity. This procedure also provides an important explanation of the curious behavior of these intuitions - in particular, why they're so easily changed by context.

\subsection{Discourses and questions}

SWEPFs typically elicit one of two contrastive reactions. One either judges that the SWEPF is false or one feels a sense of squeamishness, viz. an inability to judge whether the SWEPF is true or false. As emphasized by von Fintel (2004), the unifying characteristic of both these reactions is that the informational content of the SWEPF is rejected. For instance, if the SWEPF is asserted in the context of a discourse, then regardless of the interlocutors' particular reaction to the SWEPF, the informational content of the SWEPF is rejected from the common ground. ${ }^{16}$ The question is how to explain this prominent difference in reactions, and I suggest that an answer can be found by considering certain facts about discourse structure, discourse goals, and questions.

The central contention in this paper is that a very large class of falsity intuitions result from evaluating the content of a SWEPF in relation to a contextually salient question. The hypothesis is that when certain contextual/conversational conditions are satisfied, SWEPFs elicit intuitions of falsity. In particular, if a SWEPF is evaluated as what I label a consonant response to a contextually salient question and the relevant question has true answers, the SWEPF is judged false. The purpose of the present section is to provide a systematic and detailed explication of these conditions. I therefore adopt a theory of information structure in discourses based on Roberts $(1998,2004)$. This is a convenient framework to examine how intuitions behave in certain types of discourses, namely discourses where information exchange is the primary objective.

\footnotetext{
15 One might think that the culprit here is an exclusivity implicature which clefts are often argued to convey. However, if in the context it's clear that the identity of a single individual is sought, and thus a potential exclusivity implicature is satisfied, (33) still elicits an intuition of falsity. I thank an anonymous reviewer at L\&P for pointing this out.

${ }^{16} \mathrm{I}$ 'm deliberately ignoring cases involving presupposition accommodation, since these are irrelevant here. My concern is with cases where the interlocutors know that the presupposition is false and resist accommodation. For excellent discussions of accommodation, cf. Beaver and Zeevat (2004) and von Fintel (2008).
} 


\section{Discourse structure}

Following Roberts (1998, 2004), let's assume that the goal of a discourse is to address and answer certain questions under discussion (QUDs). ${ }^{17}$ Roberts writes,

I assume that the primary goal of discourse is communal inquiry - the intention to discover with other interlocutors" "the way things are", to share information about our world. [...] The linguistic counterpart of an inquiry is a question. Thus, we might take questions to be formal objects that reflect interlocutors' intentions in conducting discourse. (Roberts 2004, p. 208)

Let's make the additional assumption that in order to count as a discourse participant, one has an antecedent interest, or one immediately acquires an interest, in addressing or answering the QUDs-or as Roberts puts it, to count as a discourse participant is to accept a proffered question. Finally, let's assume that when a speaker engages in a discourse, the speaker is presupposing that someone in the discourse (e.g. the speaker herself) is capable of relevantly addressing or answering the QUD. Adopting this model of discourses allows us to examine the relation between reactions to SWEPFs and QUDs. In particular, it helps illustrate that the extent to which the asserted SWEPF addresses a QUD has a significant influence on our reactions to the SWEPF.

On this picture, discourses contain at least one QUD and this question is accepted by the discourse participants. The goal of the discourse is to answer the QUD, and speakers may employ different strategies to achieve that goal. One strategy is to attempt to answer the QUD, the primary question, by addressing and answering a range of subquestions. A subquestion is defined as a question entailed by the primary QUD, i.e. the question in (34) entails the subquestions $s_{1}, s_{2}, s_{3}$ etc.

What did Mary eat?

$$
\left\{\begin{array}{cc}
s_{1} & \text { Did Mary eat clams? } \\
s_{2} & \text { Did Mary eat braised short ribs? } \\
s_{3} & \text { Did Mary eat veal shanks? } \\
\vdots & \vdots \\
s_{n} & \text { Did Mary eat a tomato salad? }
\end{array}\right.
$$

This entailment relation for questions is defined as follows: (34) entails $s_{1}, s_{2}, s_{3}$ etc. because a complete and exhaustive answer to (34) would entail an answer to these subquestions. Conversely, answering a subquestion is to provide a partial answer to the primary question and answering every subquestion is therefore to provide a complete answer to the primary question. Now, on this rough picture of

\footnotetext{
17 Roberts' model relies importantly on the notions of a common ground and a context set as developed in Stalnaker (1970, 1974, 1978, 1998, 2002). On Stalnaker's theory, adding a proposition to the common ground is represented by the set theoretic operation of intersection, namely intersecting the set of worlds denoted by the proposition and the set of worlds already in the context set.
} 
discourse structure, Roberts defines a notion of relevant conversational moves. A conversational move $m$, Roberts says, is relevant to the QUD if and only if $m$ introduces a partial answer to the primary question or is part of a strategy to answer the primary question. Partial answers to a QUD can be given both directly or indirectly, i.e. one can relevantly address a QUD by asserting a sentence which (contextually) entails or implicates an answer to the QUD. Moreover, a conversational move $m$ is part of a strategy to answer the primary QUD if e.g. it proposes a subquestion to the primary QUD or serves to restrict the domain of inquiry. For example, one can propose a subquestion but restrict the domain so as to exclude certain answers as irrelevant with regards to the QUD.

\subsection{Consonance}

There are two predominant semantic analyses of questions, namely proposition-based analyses on which questions are analyzed as sets of propositions where these propositions constitute possible answers, see e.g Hamblin (1973) and Groenendijk and Stokhof (1984), and functional (or categorial) analyses on which questions are analyzed as functions from individuals to truth values, see e.g. Hausser (1983), Scha (1983), Krifka (2001, 2004). Now, since Roberts defines relevant assertions in terms of (direct or indirect) possible answers, relevant conversational moves do not include assertions that contain non-denoting DPs as constituents. Since non-denoting DPs are not mapped to individuals in a model, such assertions cannot be members of answer sets. Consequently, on both the proposition-based and the functional analyses of questions, assertions of sentences with non-referring constituents do not constitute possible answers. In this section I therefore intend to characterize an alternative set of conversational moves which are intuitively interpreted as cooperative and as addressing a QUD even if they fail to provide an answer to the QUD. So, let's say that a conversational move $m$ is consonant only if (a) the speaker intends to answer a QUD, (b) the speaker could reasonably be interpreted by the interlocutors as intending to answer the QUD, and (c) if the presuppositions of the relevant assertion were accommodated, the assertion would provide a (direct or indirect) answer to the QUD. In other words, for a conversational move to be consonant, it's strictly speaking not required that it provides an answer to the QUD, viz. a proposition/individual contained in the relevant answer set. Rather, what is required is that the conversational move could reasonably be interpreted by the interlocutors as an attempt to answer the QUD and that if its presuppositions were accommodated, it would either entail or implicate a proposition/individual contained in the answer set. On this characterization, the set of conversational moves consisting of assertions of true and false answers to a QUD is only a proper subset of the set of consonant conversational moves. The set of consonant conversational moves also contains speech acts which do not provide genuine answers to the QUD, yet are interpreted as such. The set of consonant conversational moves is a proper subset of the set of appropriate conversational moves. Not every appropriate conversational move is consonant, since not every appropriate conversational move can reasonably be interpreted as intending to answer a QUD. Here is a crude illustration. 
(35) Who ate the braised short ribs?

$\begin{array}{ll}a_{1} & \text { Mary. } \\ a_{2} & \text { Mary is a vegetarian. } \\ a_{3} & \text { I don't know. } \\ a_{4} & \text { Mary jumped the fence. }\end{array}$

+relevant / + consonant /+appropriate

+relevant / + consonant / + appropriate

-relevant / - consonant / + appropriate

-relevant / - consonant / -appropriate

The response in $\left(35-\mathrm{a}_{1}\right)$ is a genuine answer to the QUD and thus a consonant conversational move even if Mary did not eat the braised short ribs. While the response in $\left(35-\mathrm{a}_{2}\right)$ is not a direct answer to the QUD, it implicates an answer to a subquestion and is therefore also a consonant conversational move. Conversely, a response such as $\left(35-\mathrm{a}_{3}\right)$ is an inconsonant conversational move. It's inconsonant because a speaker asserting $\left(35-\mathrm{a}_{3}\right)$ is not attempting to answer the QUD. Indeed, the speaker asserts that she's not in a position to answer the question. Nevertheless, this is a perfectly appropriate response to the question insofar as the speaker fails to know the answer. Finally, the response in $\left(35-\mathrm{a}_{4}\right)$ is also an inconsonant conversational move. Here the speaker cannot reasonably be interpreted as attempting to answer the QUD. ${ }^{18}$

In the representation in (35) it seems that the set of consonant and relevant conversational moves coincide, so why is the notion of consonance needed? Consonance is designed to capture an intuitive aspect of conversational pertinence that extends beyond the set of conversational moves which provide (directly or indirectly) answers to a QUD. Where a relevant conversational move must ultimately provide an answer (directly or indirectly), a consonant conversational move need not do this. The idea is that intuitions of falsity with regards to SWEPFs depend importantly on the relation between a speech act, its content, and a given QUD, and it's this important relation which consonance is designed to capture. To characterize the set of conversational moves which give rise to falsity intuitions, a class of conversational moves extending beyond a set genuine answers is required. As I've emphasized already, if $w h$-questions are defined in terms of sets of propositions, or as functions from individuals to truth values, purported responses which contain a non-denoting DP fail to constitute a genuine answer. For example, if the relevant set of answers is a set of propositions, it won't contain any elements which have nondenoting DPs as their constituents. Similarly, if the relevant set of answers is a set of individuals, it won't contain non-existing individuals. Nevertheless, there is a clear intuitive sense in which certain responses to questions, where the asserted response contains a non-referring term, can be interpreted as a purported answer even though it's not a genuine answer to a QUD. For example, suppose we're discussing who proved Goldbach's conjecture. If I sincerely assert that the mathematician who proved Goldbach's conjecture is a woman, there is a clear sense in which my

18 On this characterization of sets of conversational moves $(\mathrm{CM})$, the following relations obtain: $\mathbf{C M}_{1} \subset \mathbf{C M}_{2} \subset \mathbf{C M}_{3}$, where $\mathbf{A}=\{p: p$ is a true or a false answer to a QUD $\}, \mathbf{C M}_{\mathbf{1}}=\{m: m$ is an assertion of $\quad p$ where $p \in \mathbf{A}\}, \mathbf{C M}_{\mathbf{2}}=\{m: m$ is consonant, $\}$ and $\mathbf{C M}_{\mathbf{3}}=\{m: m$ is appropriate/ felicitous $\}$. In other words, the set of appropriate/felicitous conversational moves is going to contain both true answers, false answers, merely purported answers, and claims of ignorance. In this characterization, answers are assumed to be propositions, but it should be obvious that it can easily be assimilated to a functional analysis of questions where e.g. single constituent questions denote sets of individuals. 
assertion is acceptable, cooperative, and addressing the QUD. Of course, no one has proved Goldbach's conjecture, so the real problem is that the discourse is defective. But despite defectiveness, my response is easily interpreted as an intended answer to the QUD. In other words, the deciding factors for obeying consonance is whether the speaker can reasonably be interpreted as answering the QUD and whether the assertion could answer the QUD were its presuppositions accommodated. Consequently, as the notions are used here, $\left(35-\mathrm{a}_{5}\right)$ is a consonant conversational move in response to (35). It's not a relevant conversational move, because it fails to provide a genuine answer (directly or indirectly) to the QUD.

as The mathematician who proved Goldbach's conjecture ate the braised short ribs. $\quad-$ relevant $/+$ consonant $/+$ appropriate

\subsection{The false intuition hypothesis (FIH)}

SWEPFs asserted in discourses are never incorporated into the common ground as partial or complete answers to a relevant QUD. The question is why SWEPFs nevertheless elicit contrasting judgments. I contend that when the content of a SWEPF is interpreted as relating to a QUD, in particular when it's interpreted as a consonant conversational move, the SWEPF elicits an intuition of falsity rather than squeamishness. The important point to emphasize is that a SWEPF is evaluated in relation to a QUD only when it's interpreted as a consonant conversational move. However, falsity judgments also depend on the relevant discourse. In particular, if a discourse is defective, i.e. if the QUD has no true answers, a consonant assertion of a SWEPF is not guaranteed to elicit a falsity judgment. The hypothesis is therefore that when an assertion of a SWEPF satisfies the conditions below, the SWEPF elicits an intuition of falsity.

(a) The SWEPF is interpreted as a consonant conversational move as regards the QUD or a subquestion to the QUD.

(b) The relevant QUD has true answers. ${ }^{19}$

But what would explain this hypothesized generalization? Why do intuitions change when these conversational conditions are satisfied? Here is a tentative explanation: A non-defective discourse contains a QUD which has true answers and the only relevant assertions in such a discourse are assertions which (directly or indirectly) provide a partial or complete answer to the QUD. Every other assertion is irrelevant. However, when we evaluate an assertion in a given discourse, the primary issue is whether the assertion succeeds in providing a true answer to the QUD, i.e. only true answers further the goal of the discourse. But in the cases under consideration here, namely assertions of SWEPFs, we're aware that the definite fails to refer, and so it's immediately clear that the assertion could not succeed in answering the QUD. As a

\footnotetext{
19 Probably, what's required here is actually a strictly speaking weaker condition, namely that the QUD is not known to have no true answers. However, I rely on this slightly simpler condition for the remainder of the paper.
} 
result the assertion is not furthering the goal of the discourse. However, if it's consonant, it's interpreted as cooperative and as an attempt to provide a true answer to the QUD. For this reason, it's grouped among consonant assertions which do not further the goal of the discourse, namely false answers to the QUD. In other words, it seems plausible that consonant assertions of SWEPFs have the same conversational status as consonant assertions of straightforwardly false non-SWEPFs. From the point of view of the discourse participants, these are simply not furthering the goal of the discourse, which is to resolve the QUD. Consequently, the SWEPFs are grouped with other consonant non-SWEPFs (viz. other false answers) and since conversational moves that further the goal of the discourse correlate with true answers, the hypothesis is that consonant conversational moves which do not further the goal of the discourse are naturally interpreted as correlating with false answers.

Before considering the predictions of the present conjecture, it's important to emphasize its scope. In some cases, a SWEPF may give rise to a falsity judgment even when the conditions of the FIH are seemingly unsatisfied. In other words, squeamishness is harder to predict. However, it's plausible that a sense of squeamishness is elicited only when at least one of the following conditions are satisfied: (a) the SWEPF is interpreted as an inconsonant conversational move, (b) the speaker is unable to determine which of several salient questions the assertion is purporting to answer, or (c) the discourse is defective.

\subsection{Predictions}

The FIH provides a straightforward explanation of the changes in truth value intuitions observed with the contextualized SWEPFs from Sect. 2, namely (28) and (29). Why do we judge that the assistant's assertion of (2) is false in the context described in (28)? The simple explanation is this: (28) is a discourse context where the QUD is arguably 'who would agree to go bald for the fashion show'. On the most easily accessible interpretation, the assistant's response is understood as a purported answer to the QUD. In other words, a consonant conversational move, but a false answer to the question. On this explication of (28), the SWEPF asserted by the assistant satisfies both conditions of the FIH and is therefore predicted to be false. This is the correct prediction, since (2) seems to elicit an immediate intuition of falsity when asserted in the context of (28).

An analogous explanation applies to (29) where the initial QUD is arguably 'should you buy croissants from Froggy Croissants?' It's subsequently determined in the discourse that the answer to that question is conditional on another question, namely whether a famous celebrity also buys croissants from Froggy Croissants. This then generates a new QUD, roughly 'which if any celebrity buys Froggy Croissants?' In response to this QUD, the salesman's assertion of (15) is again interpreted as a consonant conversational move, but a not true answer to the QUD. Both conditions of the FIH are thereby satisfied and the SWEPF is predicted to elicit falsity. Again, this is the desired prediction.

Let's consider a couple of additional examples. The SWEPFs in (36a) and (37a) seem to elicit a sense of squeamishness when evaluated as asserted abruptly and out of context. However, when these SWEPFs are interpreted as consonant responses to 
a QUD and the discourse is non-defective, it seems to me that these sentences then elicit intuitions of falsity.

(36) Who is on a state visit?

a. $\quad F$ The king of France is on a state visit.

(37) Is anyone reading Russian literature these days?

a. $F$ The king of France read Anna Karenina.

(36a) is a consonant conversational move because it's easily interpreted as a purported answer to the question in (36) and were it's presuppositions satisfied, it would constitute a genuine answer to the question. It's judged false, but this is predicted by the FIH, because both conditions are satisfied. The response in (37a) is also very easily interpreted as implicating an answer to the question in (37) and were it's presuppositions satisfied it would. This is sufficient for it to count as a consonant conversational move. Again, the SWEPF is judged false and this is predicted by the $\mathrm{FIH}$ - both conditions are satisfied.

While these cases have a relatively artificial feel, it's simple to construct these examples and they appear to confirm the FIH. I conclude this section by emphasizing that what I'm suggesting here is a general criterion for determining when and why SWEPFs are judged false; they're judged false when the relevant conditions are satisfied and they're judged false because when the relevant conditions are satisfied, the defect exhibited by the SWEPF is negligible. When a response is consonant, the speaker is not immediately interpreted as uncooperative (perhaps just confused) and this is the reason that the defect is negligible. In subsequent sections, I demonstrate that a number of prima facie perplexing cases can be explained along the lines suggested here, viz. if a SWEPF satisfies the conditions of the FIH, it's judged false.

\subsection{Consonance constraints}

One interesting class of sentences, which in certain cases could seem to constitute prima facie problems for the FIH, are SWEPFs where the non-denoting description contains a (complex) demonstrative. Uses of such descriptions, even in the context of a QUD, can elicit squeamishness rather than judgments of falsity. For instance, suppose we're engaged in a discourse, where the QUD is (38a). If a speaker asserts (38b) as an answer to this question, but demonstrates, say, an empty chair, it seems to me that this sentence fails to elicit a robust intuition of falsity.
a. Who's is bald?
b. \#The woman sitting in that chair is bald.

However, we should not accept that (38b) is a consonant conversational move. Consonance requires that it's reasonable for the interlocutors to interpret the speaker as intending to provide an answer to the QUD. However, in the discursive exchange above, this is clearly not reasonable. Since the speaker is demonstrating an empty chair, it's not feasible to ascribe to her the belief that there is woman sitting in the 
relevant empty chair. Moreover, there's no way of interpreting the speaker as simply not knowing that the chair is empty. In other words, it's not possible to interpret the speaker as if she simply assumes that the demonstrative refers while maintaining the assumption that she's cooperative. As a result, there's no way of evaluating the speaker's claim. The speaker's assertion of (38b) is therefore an inconsonant conversational move and the conditions of the FIH are not satisfied. In other words, consonance places demands on communicative cooperation. Now consider (39).
a. Who's is bald?
b. ?? The naked and invisible donkey standing in the center of the room with an iPhone in its mouth is bald.

My immediate judgment of (39b) is that it comes across as perplexing and odd rather than false. But again, I think this judgment should be explained in terms of inconsonance. The answer in (39b) is so bizarre that it obscures intuitions. Why? Because it's quite hard to attribute to the speaker the belief that there is an individual satisfying the DP restrictor 'naked and invisible donkey standing in the center of the room with an iPhone in its mouth'. Consequently, it's quite difficult to evaluate the speaker's claim. The response thus fails to count as a consonant conversational move, because the speaker asserting (39b) cannot reasonably be interpreted as cooperative and attempting to provide an answer to the QUD.

The last provisional problem for the FIH discussed here concerns cases where an answer is implicated by reporting. Consider the following question-answer pair.

(40) Who ate the braised short ribs?

a. Mary thinks that Barney ate the braised short ribs.

Insofar as the response in (40a) is consonant, it's consonant because it succeeds in implicating an answer to the QUD, namely that Barney ate the braised short ribs. Compare this to (40b) which strikes me as predominantly odd rather than straightforwardly false.

b. ?? The king of France thinks that Barney ate the braised short ribs.

If the response in (40a ) succeeds in implicating an answer to the QUD, one might be inclined to think that (40b) should also succeed in implicating an answer, namely that the king of France ate the braised short ribs. And since (40b) fails to elicit an immediate intuition of falsity, this seems to constitute a counter-example to the FIH.

The crucial question here is when and why a response such as (40a) is consonant, viz. succeeds in implicating an answer to the QUD. It seems plausible that a speaker asserting (40a) is tacitly assuming that Mary's thoughts on the issue are relevant to resolving the QUD and that the interlocutors must accept (or come to accept) this assumption. In other words, one might think that the response in (40a) is consonant only if it's common ground, or could become common ground, that Mary's opinion on the issue can help settle the question. In contrast, it's not common ground (and it could not become common ground) that the king of France's thoughts on the issue 
could help settle the question. For this reason (40b) sounds odd. I also think, in support of this explanation, that for most discourses revolving around a QUD such as (40), a response such as (40c) elicits roughly the same intuitive reactions as (40b).

\section{c. ?? Noam Chomsky thinks that Barney ate the braised short ribs.}

In other words, if a speaker offers the opinion of some individual in response to a QUD, this individual's opinion is relevant only on the supposition that she/he is likely to know the answer to the QUD. Consequently, one might think that each response above is interpreted as an answer to a subquestion, namely what the opinion of $x$ is where it can be established in the context that $x$ is an individual whose opinion is relevant to resolving the QUD. ${ }^{20}$ One might also think that the common ground determines which subquestions of this kind are relevant in a discourse, but that a speaker can introduce additional subquestions into the discourse as long as the discourse participants do not object. So if a speaker asserts (40b) in response to (40), the speaker is interpreted as addressing an irrelevant subquestion. I.e. since there is no king of France, it cannot be established in the context that the opinion of the king of France is relevant to resolving the QUD.

This explanation salvages the FIH because with respect to the primary QUD, the response in (40b) is not interpreted as providing either a partial or complete answer to the primary QUD, but rather as providing an answer to a question which is irrelevant and moreover has no true answers.

In the next section, I discuss a particular advantage of the present proposal, namely that it provides a simple and intuitive explanation of the focus cases briefly introduced earlier. No proposal for explaining the curious behavior of truth value intuitions has, to my knowledge, provided a substantial and systematic explanation of these cases.

\section{Prosodic focus}

Focus is standardly assumed to have no truth conditional effects save for interactions with focus-sensitive operators. Nevertheless, when the definite descriptions in (30-32) are focused using e.g. pitch accents, this does seem to impact immediate judgments.

$F$ The king of FRANCE is bald.

$F$ The king of FRANCE owns a pen.

\footnotetext{
20 In support of an explanation in terms of subquestions, it seems that a natural prosodic contour for the responses above involve so-called B-accented subject phrases which is the standard indicator for contrastive topics, cf. Roberts (2009). If these subject phrases function as contrastive topics, it's natural to interpret them as intended answers to additional subquestions. This relation between contrastive topics and subquestions is extensively discussed in Kadmon (2001, 2009). I discuss the effects of prosodic focusing more generally in the subsequent section. I thank an anonymous reviewer at L\&P for suggesting the explanation involving contrastive topics.
} 
$F$ The king of FRANCE always enjoys a croissant in the morning.

While these sentences normally elicit no robust intuitions, focusing appears to pull immediate intuitions towards falsity. These effects are quite curious and existing analyses of truth value intuitions are at a loss to explain them. The crucial question is how focusing affects intuitions and moreover why. However, these effects can be readily explained by the $\mathrm{FIH}$, but demonstrating this requires a minor digression. In the subsequent paragraphs I therefore provide a brief explication of the notion of prosodic focus and present an analysis of its pragmatic and semantic properties.

In a variety of languages (incl. English) pitch accents are used to realize prosodic focus. Intuitively, speakers use prosodic focusing in order to contrast the focused material with something already salient in the discourse. For instance, the use of prosodic focus is particularly prevalent when speakers attempt to emend incorrect information in a discourse. This is typically labeled 'contrastive focus' and illustrated in (41).

(41) a. Mary ate clams.

b. No, JOHN ate clams.

On standard analyses, it's assumed that prosodic focus divides the content of an expression into two parts, the background and the focus. The background is construed as information which is already given in the context, whereas the focused material is construed as new information. Alternatively, one might roughly say that focus-marked material is information intended to be added to the common ground, whereas the non-focused material (the backgrounded material) is assumed to be antecedently established. This division of the content can be neatly represented using function/argument pairs, where the backgrounded information is represented by a function and the new information is represented by an argument (cf. the (c)-cases below).
a. MARY ate clams. $\Rightarrow$
b. $\langle$ Background, Focus $\rangle \Rightarrow$
c. $\langle\lambda x . x$ ate clams, Mary
a. Mary ATE clams. $\Rightarrow$
b. $\langle$ Background, Focus $\rangle \Rightarrow$
c. $\langle\lambda R$.Mary $R$ clams, eat $\rangle$

(44) a. Mary ate CLAMS. $\Rightarrow$

b. $\langle$ Background, Focus $\rangle \Rightarrow$

c. $\langle\lambda x$. Mary ate $x$, clams $\rangle$

Although focus is realized by pitch accenting single words or syllables, it's generally accepted that focus often extends to larger syntactic constituents (i.e. DPs, VPs etc.). Even though the pitch accents in (30-32) are placed on the proper name 
'France', the focus-marking can extend to the entire DP. The problem of understanding the relation between prosody and focus-marking-sometimes referred to as focus projection - has spawned a lively discussion which I'll refrain from engaging in here. However, it should be noted that focal scope places important restrictions on use. So, in order to distinguish focus-marking from particular prosodic realizations of focus, I'll indicate focal scope using square brackets with a subscripted $f$, and use capitals to indicate pitch accents. So, (30-32) should be represented as below.

${ }^{F}$ [The king of FRANCE $]_{f}$ is bald.

${ }^{F}$ [The king of FRANCE $]_{f}$ owns a pen.

${ }^{F}$ [The king of FRANCE $]_{f}$ always enjoys a croissant in the morning.

\subsection{Structured meanings: the semantics and pragmatics of focus}

It's generally assumed that there is an important relation between the semantic and pragmatic effects of focus and the semantics of questions. The currently predominant semantic analyses focus, namely Alternative Semantics and Structured Meanings, are therefore extensions of the currently predominant analyses of questions. In particular, Alternative Semantics is a proposition-based analysis extending the proposition-based semantic analysis of questions, whereas Structured Meanings is a functional analysis, extending the functional semantic analysis of questions. In the exposition here, I use a Structured Meanings analysis, but I want to emphasize that an analysis using Alternative Semantics makes identical predictions. ${ }^{21}$

On the functional analysis of questions, as previously mentioned, wh-questions denote functions from individuals to truth values which are obtained by lambdaabstracting on the wh-phrases (or rather the denotations of the wh-phrases). This analysis therefore assigns a very intuitive meaning to questions, namely a function which takes answers as its arguments. A question such as (45a) is therefore analyzed as (45b).

$$
\begin{aligned}
& \text { a. What did Mary eat? } \\
& \text { b. } \lambda x \text {. Mary ate } x
\end{aligned}
$$

$\leftarrow \lambda$-abstracting on the $w h$-phrase

The Structured Meanings account of focus extends the basic idea in the Structured Meanings semantics for questions. Focus-induced interpretations of sentences are obtained by lambda-abstracting on the focus-marked constituents. This produces the focus-induced structured meaning of the sentence, namely an ordered sequence

\footnotetext{
21 Structured Meanings is discussed in Stechow (1989, 1991), and Krifka (1991, 2001). Alternative Semantics was introduced by Mats Rooth in (1985) and further discussed in Rooth $(1992,1996)$. These theories diverge in important respects, but the differences only emerge at a fairly detailed level of analysis. As regards the cases under consideration here, the predictions of these two theories are identical. Illuminating discussions are available in Kadmon (2001) and Beaver and Clark (2008).
} 
whose members are a property (a function) and an individual (an argument). This analysis of focus is represented in (42) - repeated below.

$$
\begin{aligned}
& \text { a. }[\mathrm{MARY}]_{f} \text { ate clams. } \\
& \text { b. }\langle\lambda x . x \text { ate clams, Mary }\rangle
\end{aligned}
$$

Given this analysis, recovering semantic content, viz. truth conditional content, is straightforward, but it also provides a useful resource for explaining various effects. For instance, semantic effects observed when focused elements interact with focussensitive particles and pragmatic effects such as question-answer congruence.

A common observation in the study of focus is that focus restricts the set of contexts in which sentences can be felicitously asserted. The paradigm example of this effect is question-answer pairs. The general observation is that focus-marked sentences asserted in response to wh-questions are felicitous only if the focusmarked constituent is correlated with the $w h$-phrase of the particular question. ${ }^{22}$ For example, consider the question (46) and each response in (46a-46c). Observe that responses where the focus-marked constituent is not correlated with the wh-phrase are infelicitous.

(46) What did Mary eat?

a. Mary ate $[\text { CLAMS }]_{f}$.

b. *Mary $[\mathrm{ATE}]_{f}$ clams.

c. $\quad *[\mathrm{MARY}]_{f}$ ate clams

A useful way of thinking about the constraints on assertion induced by focus is that focus constrains the questions that the sentence can felicitously answer. The Structured Meanings analysis provide a straightforward explanation of these restrictions on use. Since focus-induced interpretations are derived by lambdaabstracting on the focus-marked constituents, this procedure provides a method for determining which questions the focus-marked sentence is most naturally understood as purporting to answer. It can only felicitously answer questions with a denotation that corresponds to the function obtained from abstraction on the focus, cf. (45b).

\subsection{Focus and non-referring definites}

The close correlation between questions and focus provides a simple and intuitive explanation of the changes in truth value intuitions noted in the beginning-cf. (30-32). The explanation is that focus-marking fixes the questions that the sentence can felicitously answer. With no focus-marked constituents, (30-32) could serve as felicitous answers to different questions, but the result of focusing the DPs in (30-32) is that these sentences are now most naturally interpreted as providing an answer to a specific question.

$\overline{22}$ Cf. Rooth (1996), Krifka (2001), and Kadmon (2001) for discussion. 
(47) a. [The king of FRANCE $]_{f}$ is bald.

b. $\langle\lambda x . x$ is bald, the king of France $\rangle$

c. $\lambda x . x$ is bald

$\leftarrow \lambda$-abstracting on the focus

d. Who is bald? $\leftarrow$ derived function

$\leftarrow$ the relevant question

(48) a. [The king of FRANCE $]_{f}$ owns a pen.

b. $\langle\lambda x . x$ owns a pen, the king of France $\rangle \leftarrow \lambda$-abstracting on the focus

c. $\lambda x . x$ owns a pen

d. Who owns a pen?

$\leftarrow$ derived function

$\leftarrow$ the relevant question

(49) a. [The king of FRANCE $]_{f}$ always enjoys a

croissant in the morning.

b. $\langle\lambda x . x$ always enjoys a croissant in the morning, the king of France $\rangle$

c. $\lambda x . x$ always enjoys a croissant in the morning

d. Who always enjoyes a croissant in the morning?

$\leftarrow \lambda$-abstracting on the focus

$\leftarrow$ derived function

$\leftarrow$ the relevant question

$\lambda$-abstraction on the focus yields an ordered sequence, a function and an argument. The derived function is the denotation of a question, namely the denotation of a whquestion where we've $\lambda$-abstracted on the $w h$-phrase. Hence, we've obtained a simple method for determining which question these sentences are most naturally interpreted as answering.

(30-32) elicit intuitions of falsity and given the analysis above this is also predicted by the FIH. The (a) condition is satisfied, because (30-32) are most easily interpreted as responses to particular questions and therefore as consonant conversational moves. The (b) condition is satisfied, because the questions against which each of these sentences are evaluated have true answers (cf. the questions above). The prediction of the hypothesis is therefore that these sentences should elicit immediate intuitions of falsity and I believe the data verifies this prediction.

The hypothesis that there is a systematic connection between robust intuitions of falsity and consonant conversational moves, i.e. putative answers to QUDs, is thus supported by the cases involving focus. But, in order to evaluate in more detail the predictions of the present hypothesis, it's instructive to consider what happens if we change focus-structure in (30-32). Interestingly, it seems that the result of focusing constituents outside the non-referring DP is again a change in intuitions. In particular, I find that there is a clear contrast between (30-32) and (50-52).

\#The king of France is $[\mathrm{BALD}]_{f}$

(51) \#The king of France owns $[\mathrm{a} \mathrm{PEN}]_{f}$

(52) \#The king of France always enjoys [a CROISSANT $]_{f}$ in the morning. 
These cases seem to me to elicit a sense of squeamishness rather than falsity. Out of context assertions of (50-52) are distinctly odd rather than obviously false. But why is there this marked difference in intuitions when the focus-marking is changed from the non-referring subject DP to a constituent in the VP? Let's again analyze these constructions.

(53) a. The king of France is $[\mathrm{BALD}]_{f}$.

b. $\langle\lambda R$. The king of France is $R$, bald $\rangle \leftarrow \lambda$-abstracting on the focus

c. $\lambda R$. The king of France is $R$

$\leftarrow$ derived function

d. The king of France is what?

$\leftarrow$ the relevant question (what is the king of France like?)

(54) a. The king of France owns $[\mathrm{a} \mathrm{PEN}]_{f}$.

b. $\langle\lambda P$. The king of France owns $P$, a pen $\rangle \quad \leftarrow \lambda$-abstracting on the focus

c. $\lambda$ P. The king of France owns $P$ $\leftarrow$ derived function

d. The king of France owns what?

$\leftarrow$ the relevant question (what does the king of France own?)

(55) a. The king of France owns always enjoys [a CROISSANT] $]_{f}$ in the morning.

b. 〈 $\lambda P$. The king of France always enjoys $P$ in the morning, a croissant $\rangle$

c. $\lambda P$. The king of France always enjoys $P$ in the morning.

d. The king of France always enjoys what in the morning?

(what does the king of France always enjoy in the morning?)

$\leftarrow \lambda$-abstracting on the focus $\leftarrow$ derived function

$\leftarrow$ the relevant question

Given this analysis, it's unsurprising that these sentences elicit squeamishness when constituents outside the non-referring DP are focus-marked, because this produces a different question-answer structure. The sentences in (50-52) are most naturally interpreted as answering different questions than the sentences in (30-32), namely questions which lack true answers. Absent heavy duty contextual assumptions, there are no true answers to a question about what a non-existing entity is like and a discourse revolving around a QUD which has no true answers is a defective discourse. As a result, these sentences are most naturally interpreted as consonant answers in a defective discourse. This result is consistent with the FIH. The sentences (53-55) satisfy the (a) condition, because despite the fact that the relevant questions have no true answers these sentences are naturally interpreted as consonant conversational moves. However, since the relevant questions have no true answers, (53-55) fail to satisfy the (b) condition. Again, this supports the hypothesis that falsity intuitions are a result of evaluating sentences with respect to 
QUDs-namely QUDs which have true answers (or are not known to have no true answers). ${ }^{23}$

\section{Extending the proposal}

\subsection{Complex constructions and intensional interpretations}

The problem of conflicting truth value intuitions, as ordinarily conceived, concerns a puzzling and apparently non-systematic distribution of truth value judgments. In short, the problem is explaining why some SWEPFs elicit judgments of falsity while others elicit a sense of squeamishness. However, if complex/intensional cases are taken into consideration, this distribution appears to break down. In particular, it seems that complex/intensional SWEPFs often give rise to robust judgments of truth. Consider for example (56).

\section{Who does Mary fear?}

a. Mary fears the king of France.

If Mary believes that there is a king of France and also fears the king of France, it seems that (56a) is true. It also seems that an adequate semantic analysis should be able to predict this. However, the truth of (56a) clearly depends on an intensional interpretation of the sentence. (56a) cannot be judged true unless it's assumed that Mary believes in the existence of a French king. In contrast, suppose it's common ground that Mary knows that there is no king of France. In this case, i.e. where (56a) is interpreted extensionally, I think there's a natural inclination to judge (56a) false. And this is what the FIH predicts.

In other words, explaining truth value intuitions as regards complex/intensional cases is a quite different project than explaining truth value intuitions as regards non-complex/extensional cases. First, the distribution of intuitions is, for various reasons, entirely different in the complex cases. Secondly, it's widely agreed that a proper semantic analysis of complex constructions requires a more general discussion of the semantics of modals, i.e. epistemic and root modals, attitude verbs, if-clauses, but also the full range of logical connectives. This is obviously a rather daunting task. I therefore think that it's quite reasonable to assume that complex cases, and in particular intensional cases, should be set aside. There are good

\footnotetext{
23 One potential problem for the account sketched here is multiple focus constructions, where one of the focused constituents is a non-referring DP. While I'm not confident that the data from such cases is entirely stable, it seems that these elicit falsity judgments less frequently. A similar problem arises for discourse contexts with multiple constituent questions, viz. questions which contain two wh-phrases such as 'who ate what?'. Multiple constituent questions and multiple focus constructions are already a point of controversy in the literature on the semantics and pragmatics of focus, cf. e.g. Krifka (1991, 2001), so how to resolve these potential problems is a delicate issue. An in-depth discussion would require at least a serious study of the relevant data and plausibly a more detailed and more complex story about prosody, focus-distribution, and question-answer congruence. The aim of this paper is to provide a fairly programmatic account of the relation between truth value intuitions and context, so I eschew a discussion of these potential problems here.
} 
reasons to believe that intuitions about such cases must be explained along quite different lines and involve a range of considerations which are not relevant in noncomplex/extensional cases. ${ }^{24}$ This, I take it, is also the reason that complex/ intensional cases are rarely discussed in the literature on the present problem. So, while (56a) is a putative counter-example to the FIH (i.e. both conditions of the FIH are satisfied, yet one reading of the sentence fails to elicit a sense of falsity), it is a counter-example only on an intensional reading. However the FIH should be understood as a hypothesis which aims to explain a particular distribution of intuitions about non-complex/extensional cases—not complex/intensional cases.

Now, having set complex/intensional cases aside, one might nevertheless worry whether my proposal is extendable to SWEPFs evaluated as asserted abruptly and out of context. The prima facie problem is that an explanation of such non-contextualized SWEPFs appears to preclude appeals to discourse contexts or QUDs. In the next sections, I therefore provide a rough sketch of an explanation of how noncontextualized cases can be assimilated to the present proposal. ${ }^{25}$

\subsection{Out-of-context SWEPFs}

The notion of evaluating sentences as asserted abruptly and out of context is frequently used in the literature, but it should be agreed that assertions cannot occur out of context. Any assertion, real or imagined, must occur against the background of some contextual assumptions. This much is uncontroversial. But for that very reason, it's hard to believe that we are capable, in any substantial sense, of evaluating SWEPFs as asserted abruptly and out of context. The question then is what process is invoked and against what contextual assumptions we are evaluating the sentences. A plausible answer is that we evaluate the sentence by trying to determine which question an assertion of the sentence is intended to address. If so, an explanation of the distribution of intuitions as regards non-contextualized cases is that if it's determined that the assertion is intended to address a question which is known to have no true answer, it elicits a sense of squeamishness. Similarly, if it cannot be determined which question the assertion is intended to address or the question cannot be answered, this also gives rise to a sense of squeamishness. In contrast, one might think that SWEPFs elicit an intuition of falsity when it's determined and interpreted as an intended answer to a question which is not known

\footnotetext{
24 For example, a presuppositional analysis should not predict truth value gaps for every complex sentence containing a non-denoting definite, i.e. when embedded in modal constructions, conjunctions, conditionals etc. It's standardly assumed that an adequate account of presupposition projection is what's required to avoid this consequence and the current literature contains numerous attempts to provide such an account. In contrast, while a standard Russellian analysis of definites is capable of computing classical truth values for definites embedded in complex constructions, this requires a range of not unproblematic assumptions about scopal ambiguities, see e.g. Fodor (1970), and Bäuerle (1983). For related problems with an existential analysis and modal verbs see Heim (1991), Elbourne (2005, 2009), and Schoubye (2010).

25 I should emphasize that the aforementioned accommodation theories are not obviously inconsistent with my proposal. While I've argued that these theories suffer from certain inadequacies, one could, I believe, combine my analysis with e.g. von Fintel's (2004) analysis of non-contextualized cases. From the point of view of theoretical parsimony, a uniform account is obviously desirable, but it's perfectly conceivable that different explanations are required in order to account for the full range of data.
} 
to have no true answers. The conjecture is thus that these robust intuitions also result from evaluating the SWEPF against a particular question-a question which the evaluator for various reasons interprets the sentence as addressing. What requires explaining is how relevant questions are identified and how evaluators select among them. Below I provide a rough sketch of an answer to this question.

\subsection{Discourse topics and practical relevance}

Successful discourse comprehension depends crucially on determining what information an assertion is intended to convey-e.g. what question an assertion is intended to address. One particularly important interpretative task is therefore determining the topic of discussion. In simple subject-predicate constructions, one might think that absent contextual information there is a natural inclination to interpret the grammatical subject of a sentence as the topic where topic is understood as the topic of the discourse or a question under discussion. While topics in the sense of particular syntactic constituents, i.e. grammatical subjects, and topics in the sense of QUDs must not be conflated (cf. Roberts 2009), it's not implausible that these are conflated in discourse interpretation when no information about the discourse context is supplied. This fact helps explain a particular pattern of truth value intuitions which was observed by Strawson, namely that when a non-denoting DP occurs in a sentence as the grammatical subject, the sentence is liable to elicit a sense of squeamishness. In contrast, when a non-denoting DP occurs as grammatical object (or as a prepositional object), the sentence is liable to elicit an intuition of falsity. Indeed, it's actually somewhat difficult to find examples of sentences with non-denoting DPs in object position which elicit a sense of squeamishness. This contrast is captured in Strawson's famous examples (57-58) and this furnished the grounds for Strawson's proposed analysis.

\# The king of France visited the Exhibition.

(Strawson 1964)

$F$ The Exhibition was visited by the king of France.

If Strawson's observation about these cases is correct, it provides an explanation of a range of non-contextualized SWEPFs which is consistent with the FIH. If the grammatical subjects are interpreted as topical, i.e. as the topic of discussion, these DPs are naturally interpreted to be part of the question that is being addressed. In other words, the non-denoting DPs are treated as given. This means that a sentence such as (57) is naturally interpreted as addressing a question about the king of France whereas (58) is naturally interpreted as addressing a question about the exhibition. This provides a straightforward explanation of the distribution of intuitions which is consistent, indeed predicted, by the FIH.

While this explanation helps explain a range of cases, it's insufficiently general. We've already encountered a variety of SWEPFs with non-denoting DP subjects which nevertheless elicit intuitions of falsity. This is one of the reasons that Strawson's proposed analysis fails. However, Strawson's comments on the observed contrast are quite illuminating. 
We might, for example, have felt a shade more squeamish if we had written 'The king of France visited the Exhibition yesterday' instead of 'The Exhibition was visited yesterday by the king of France'. We feel very squeamish indeed about 'The king of France is bald' presented abruptly, out of context, just because we don't naturally and immediately think of a context in which interest is centred, say, on the question What bald notables are there? rather than on the question What is the king of France like? or Is the king of France bald? Of course, to either of these two questions the statement would not be just an incorrect answer. These questions have no correct answer. (Strawson 1964, pp. 68-69)

Strawson raises an interesting question, namely how interest is centered in sentence evaluations. While there might be a natural inclination to interpret grammatical subjects as topical, i.e. as subjects under discussion, it's possible that this natural inclination is sometimes overridden, for example when certain constituents are prosodically focused. Another factor which could plausibly impact how interests are centered on specific questions is practical relevance. For example, it seems quite likely that evaluators are liable to interpret sentences as addressing a specific question if that question is somehow pertinent to their interests. For example, consider the SWEPFs below which seem to elicit intuitions of falsity even when evaluated without any information about the discourse context.

$F$ The king of France hates your mother.

(60) $F$ The king of France is planning to bomb your city.

These sentences could felicitously answer a wide range of questions, but absent contextual information, these would be most naturally interpreted as responses to one of the two questions in (61) and (62) respectively.

(61) a. Who hates your mother?

b. Who does the king of France hate?

(62) a. Who is planning to bomb your city?

b. What is the king of France planning to bomb?

The hypothesis here is that speakers engaged in discourse interpretation select among immediately available questions with a default to interpreting grammatical subjects as topical. If nothing prompts selecting a particular question, the grammatical subject is assumed to be the topic of discussion. However, if one of the available questions is practically relevant to the evaluator and is assumed to have true answers, the evaluator's interest is centered on that question and the default interpretation of the grammatical subject as topical can thereby be overridden. If so, the sentence is interpreted as addressing that question, rather than the other available question. For example, if (59) triggers the questions in (61), the question (61a) has a 
clear practical relevance to most people, viz. most people have an interest in the answer to that question. In contrast, the question in (61b) has no practical relevance to most people. If this is right, evaluators should normally select the (a) questions rather than the (b) questions which are known to have no true answers. And if that's the case, then (59) and (60) should both elicit intuitions of falsity-which they do. This line of reasoning should then also explain why an out-of-context assertion of a SWEPF such as (2) elicits squeamishness; both questions triggered by a sentence such as (2) are practically irrelevant, and as a result evaluators default to an interpretation on which the non-denoting DP is topical. This yields a prediction consistent with the FIH. However, for this idea to work, practical relevance must be construed quite broadly. For example, if a putative answer to a question would be controversial or out of the ordinary, this is sufficient for it to be practically relevant. A good analogy here is the process of presupposition accommodation. It's fairly well established that speakers often refuse to accommodate presuppositions if the presupposed contents are controversial or out of the ordinary. I believe that something quite similar is going on in the cases under consideration here. If an assertion is interpreted as providing an answer to a question where the answer would be controversial or out of the ordinary, speakers are liable to center their interest on that particular question. This would for example explain the contrast between (2) and (3-4) and also why there is a contrast in intuitions between the two sentences below.
a. \#The king of France lives in castle.
b. ${ }^{F}$ The king of France lives in a spaceship.

I acknowledge that this explanation amounts, at best, to a very rough sketch of a general strategy for explaining non-contextualized cases. To carry real weight, the notion of practical relevance must explicated in much more detail and even then a number of additional psychological and pragmatic factors must be taken into consideration. However, it would be no surprise if explaining and determining how interest is centered in discourse interpretation turns out to be exceedingly complex. It's beyond any reasonable doubt that informational contents play a very important role in the generation of truth value intuitions, so a complete story about interest-centering must in all likelihood include an account of the relation between informational contents and speaker's interests, desires, intentions and so on. In other words, the really complicated step in analyzing these recalcitrant noncontextualized cases is to explain why, and predict when, evaluators select particular questions. The very rough explanation above is merely a crude example intended to convince you that psychological factors could play a potentially crucial role. If nothing else, one might think that the extremely complex behavior of non-contextualized SWEPFs is a good reason not to rely on such cases in our semantic theorizing. Thus, what I'm advocating is a methodological switch to contextualized cases, since these are more stable and more easily explained. To rely solely on non-contextualized cases requires that a satisfactory theory of interest-centering is available. 


\section{Existential versus. presuppositional analyses}

I stated in the introduction that the present proposal provides prima facie support for a presuppositional analysis of definites. The reason is that if my proposed analysis is correct, i.e. if intuitions of falsity are the result of a particular relation of conversational pertinence obtaining between speech acts, their contents, and QUDs, this seems to support the conclusion that falsity intuitions are a result of factors which look prima facie irrelevant to semantics. In particular, the fact that a sentence elicits an intuition of falsity when its expressed content relates in a suitable way to a QUD seems to reveal nothing significant about the semantic status of that sentence, e.g. its truth value. This puts some pressure on an analysis which maintains that these sentences should be assigned classical truth values. In particular, proponents of such an analysis must explain why these intuitions really are semantically relevant despite the fact that they seem to track various pragmatic factors.

In response, proponents of a Russellian analysis might be tempted to adopt the present proposal and argue that squeamishness occurs because the contents of the relevant sentences fail to relate to a QUD - the failure of conversational pertinence simply is the reason that some SWEPFs elicit squeamishness. In other words, the Russellian might attempt to adopt the present proposal only with the order of explanation reversed. Here it should be noted that this strategy is not immediately feasible. My analysis supplies only a sufficient condition for determining when SWEFPs elicit falsity judgments, not a necessary condition and if the explanation is to work in the opposite direction, i.e if we are to explain the squeamishness intuitions in general, a necessary condition is needed. Of course, this is essentially a shortcoming of my proposal since determining both necessary and sufficient conditions is desirable for independent reasons. Nevertheless, it's important to emphasize that such a necessary condition must be established if the Russellian is to employ the present proposal as an explanation of the variance in truth value intuitions. Yet, even if a necessary condition is determined, there remains a couple of issues for the Russellian to address. For example, if falsity judgments track the semantic status of these sentences, why is there such an intimate relation between conversational pertinence and truth value intuitions. On the present proposal, robust intuitions of falsity are inherently related to the thoroughly pragmatic notion of consonance, but we should not expect such pragmatic factors to influence intuitions which do track the semantic status of the sentences. If these are genuine semantic intuitions, why are they so closely correlated with the satisfaction of various pragmatic conditions.

Secondly, it seems that if conversational pertinence plays as crucial a role, as I've suggested here, we should expect squeamishness to occur much more often. But if we're engaged in a discussion about, say, who won the Super Bowl, and I assert (64), this assertion appears to elicit no immediate squeamishness as regards its truth value.

Barack Obama is a Russian astronaut.

This assertion is inconsonant, indeed inappropriate, but I nevertheless think that there is no immediate hesitation to judge it false. However, if the Russellian is right 
that the simple lack of conversational pertinence is what causes squeamishness intuitions, squeamishness should occur for a whole range of sentences when these are inconsonantly asserted in discourse. It seems somewhat questionable whether there is such a general effect.

A presuppositional analysis of definites typically analyzes definite determiners as partial functions, which are defined only for a subset of the domain of $\langle e, t\rangle$-functions. If squeamishness tracks semantic defectiveness, it seems quite appropriate to capture this in a semantic analysis in terms of an undefined function. I therefore take it that the presuppositional analysis of SWEPFs has a prima facie, but non-trivial, empirical advantage over an existential analysis.

\section{Concluding remarks}

The problem of conflicting truth value intuitions is often dismissed as intractable, unimportant, and as a result uninteresting, see e.g. Geurts (1999, pp. 29-30). Here I've attempted to demonstrate that this problem is important, that it's not intractable, and that it is interesting. I have focused exclusively on the definite determiner, but it would ultimately be desirable to extend the proposed analysis here to the full range of putatively presuppositional DPs and perhaps to presuppositional expressions in general. Since incorporating other determiners into the present analysis would almost surely introduce a number of additional complexities, I've focused on providing a concrete and immediately plausible proposal for understanding the relation between truth value intuitions and non-referring definites. I've argued that falsity intuitions are the result of a particular interpretational mechanism; robust intuitions arise when SWEPFs are evaluated in relation to QUDs and judging a SWEPF false is therefore equivalent to (tacitly) recognizing that the SWEPF is an intended, but not true, answer to the relevant QUD. In other words, judgments of falsity track whether a SWEPF is a member of a set of true answers. The behavior of contextualized SWEPFs seem to conform to this explanation and I've gestured towards a similar explanation of non-contextualized SWEPFs as well. Given the available data, I've advocated a methodological switch, but assuming that the data from noncontextualized cases is relevant, the remaining key problem is determining how, in the non-contextualized cases, speakers select particular questions. In conclusion, much work remains to be done, but hopefully the proposal here can serve as a general explanatory strategy.

Acknowledgements I'm particularly grateful to Herman Cappelen, Dilip Ninan and Jonathan Schaffer for providing invaluable comments on several drafts of this paper. The paper has also improved significantly through discussion, comments, and helpful suggestions from Nicholas Allott, Derek Ball, Nate Charlow, Josh Dever, Guămundur Andri Hjálmarsson, Torfinn Huvenes, Michael Glanzberg, Craige Roberts, Daniele Sgaravatti, Andreas Stokke, and Kjell Johan Sæbø. Finally, I thank the organizers and audiences at the Contextualism and Relativism seminar at Arché (University of St Andrews), The Danish Epistemology Network Workshop (University of Copenhagen), the Language and Rationality Seminar at CSMN (University of Oslo), and Linguistic Intuitions Workshop at CSMN (University of Oslo). 


\section{References}

Bäuerle, R. (1983). Pragmatischsemantische Aspekte der NP-Interpretation. In M. Faust, R. Harweg, W. Lehfeldt, \& G. Wienold (Eds.), Allgemeine Sprachwissenschaft, Sprachtypologie und Textlinguistik. Tübingen: Narr.

Beaver, D. I., \& Clark, B. Z. (2008). Sense and sensitivity: How focus determines meaning. Chicester, UK: Wiley Blackwell.

Beaver, D. I., \& Zeevat, H. (2007). Accommodation. In G. Ramchand \& C. Reiss (Eds.), Oxford handbook of linguistic interfaces (pp. 503-539). Oxford: Oxford University Press.

Elbourne, P. (2005). Situations and individuals. Cambridge, MA: MIT Press.

Elbourne, P. (2008). The existence entailments of definite descriptions. Available from http://semanticsarchive.net/Archive/mFlNDgwN/teeodd.pdf (Unpublished ms.)

Fodor, J. D. (1970). The linguistic description of opaque contexts. Ph.D. thesis, Massachusetts Institute of Technology. Published in 1976 by Indiana University Linguistics Club and in 1979 in the Garland Series Outstanding Dissertations in Linguistics.

Frege, G. (1892). On Sinn and Bedeutung. In M. Beaney (Ed.), The Frege reader (1997) (pp. 151-172). Oxford: Blackwell Publishing.

Frege, G. (1918). The thought. In M. Beaney (Ed.), The Frege reader (1997) (pp. 325-346). Oxford: Blackwell Publishing.

Geurts, B. (1999). Presuppositions and pronouns. Oxford: Elsevier.

Geurts, B. (2007). Existential import. In I. Comorowski \& K. von Heisinger (Eds.), Existence: Syntax and semantics (pp. 253-271). Dordrecht: Springer.

Glanzberg, M. (2005). Presuppositions, truth values, and expressing propositions. In G. Preyer \& G. Peters (Eds.), Contextualism in philosophy: Knowledge, meaning, and truth. Oxford: Oxford University Press.

Groenendijk, J., \& Stokhof, M. (1984). Studies on the semantics of questions and the pragmatics of answers. Doctoral Dissertation, University of Amsterdam.

Hamblin, C. L. (1973). Questions in Montague English. Foundations of Language, 10, 41-53.

Hausser, R. (1983). The syntax and semantics of English Mood. Questions and answers. Dordrecht: Reidel.

Heim, I. (1991). Artikel und Definitheit. In A. von Stechow \& D. Wunderlich (Eds.), Semantik: ein internationale Handbuch der zeitgenössichen Forschung (pp. 487-535). Berlin: Walter de Gruyter.

Kadmon, N. (2001). Formal pragmatics. Oxford: Blackwell Publishing.

Kadmon, N. (2009). Contrastive topics and the focal structure of questions. Available from http:// semanticsarchive.net/Archive/jMzOTczN (Unpublished ms.)

Krifka, M. (1991). A compositional semantics for multiple focus constructions. Proceedings of SALT 1. Cornell University Working Papers in Linguistics, Ithaca, NY.

Krifka, M. (2001). For a structured meaning account of questions and answers. Audiatur Vox Sapientia. A Festschrift for Arnim von Stechow (pp. 287-320). Berlin: Academie Verlag.

Krifka, M. (2004). The semantics of questions and the focusation of answers. In Topic and focus: A crosslinguistic perspective (pp. 139-151). Dordrecht: Kluwer.

Lasersohn, P. (1993). Existence presuppositions and background knowledge. Journal of Semantics, 10, $113-122$.

Neale, S. (1990). Descriptions. Cambridge, MA: MIT Press.

Roberts, C. (1998). Information structure in discourse: Towards an integrated formal theory of pragmatics. In J.-H. Yoon, \& A. Kathol (Eds.), OSU working papers in linguistics: Vol. 49: Papers in semantics. Columbus, OH: Deptartmen of Linguistics, Ohio State University.

Roberts, C. (2004). Context in dynamic interpretation. In L. R. Horn \& G. Ward (Eds.), Handbook of pragmatics (pp. 197-221). Oxford: Blackwell Publishing.

Roberts, C. (2009). Forthcoming in C. Maienborn, K. von Heusinger, P. Portner (Eds.), An international handbook of natural language meaning. Berlin: Mouton de Gruyter.

Rooth, M. (1985). Association with focus. Doctoral Dissertation, University of Massachusetts, Amherst. Rooth, M. (1992). A theory of focus interpretation. Natural Language Semantics, 1.1, 75-116.

Rooth, M. (1996). Focus. In S. Lappin (Ed.), Handbook of contemporary semantic theory (pp. 271-297). Oxford: Blackwell.

Russell, B. (1905). On denoting. Mind, 14, 479-493.

Russell, B. (1957). Mr. Strawson on referring. Mind, 66, 385-389.

Scha, R. (1983). Logical foundations for question answering. Doctoral Dissertation, Groningen University. 
Schoubye, A. J. (2010). Some presuppositions. http://www.schoubye.org/papers/SP.pdf (Unpublished ms.)

Stalnaker, R. C. (1970). Pragmatics. Synthese, 22(1/2), 272-289.

Stalnaker, R. C. (1974). Pragmatic presuppositions. In M. Munitz \& P. Unger (Eds.), Semantics and philosophy. New York: New York University Press.

Stalnaker, R. C. (1978). Assertion. In P. Cole (Ed.), Syntax and Semantics 9 (pp. 315-332). New York: Academic Press.

Stalnaker, R. C. (1998). On the representation of context. Journal of Logic, Language, and Information, 7 , $3-19$.

Stalnaker, R. C. (2002). Common ground. Linguistics and Philosophy, 25 (701-721).

Strawson, P. F. (1950). On referring. Mind, 59, 320-344.

Strawson, P. F. (1952). Introduction to logical theory. London: Methuen.

Strawson, P. F. (1964). Identifying reference and truth-values. Theoria, 30, 96-118 (Reprinted in P. F. Strawson Logico-Linguistic Papers, Ashgate, London 1971).

van der Sandt, R. (1992). Presupposition Projection as Anaphora Resolution. Journal of Semantics, 9 , 333-377.

von Fintel, K. (2004). Would you believe it? The King of France is back! (Presuppositions and truth-value intuitions). In A. Bezuidenhout \& M. Reimer (Eds.), Descriptions and beyond (pp. 315-342). Oxford: Oxford University Press.

von Fintel, K. (2008). What is presupposition accommodation, again? Philosophical Perspectives, 22(1), 137-170.

von Stechow, A. (1989). Focusing and background operators. In Arbeitspapier $n r$. 6. Fachgruppe Wissenschaft, Universität Konstanz.

von Stechow, A. (1991). Current issues in the theory of focus. In von Stechow \& D. Wunderlich (Eds.) Semantik/semantics: An international handbook of contemporary research (pp. 804-825). Berlin: de Gruyter.

Yablo, S. (2006). Non-catastrophic presupposition failure. In J. J. Thomson \& A. Byrne (Eds.), Content and modality: Themes from the philosophy of Robert C. Stalnaker. New York: Oxford University Press.

Yablo, S. (2009). Must existence-questions have answers? In D. J. Chalmers, D. Manley, \& R. Wasserman (Eds.), Metametaphysics: New essays on the foundations of ontology (pp. 507-525). Oxford: Oxford University Press. 